This document is confidential and is proprietary to the American Chemical Society and its authors. Do not copy or disclose without written permission. If you have received this item in error, notify the sender and delete all copies.

\title{
Guiding Principles of Hydrogenase Catalysis Instigated and Clarified by Protein Film Electrochemistry
}

\begin{tabular}{|r|l|}
\hline Journal: & Accounts of Chemical Research \\
\hline Manuscript ID & ar-2016-000272.R1 \\
\hline Manuscript Type: & Article \\
\hline Date Submitted by the Author: & 09-Mar-2016 \\
\hline Complete List of Authors: & $\begin{array}{l}\text { Armstrong, Fraser; Oxford University, Chemistry } \\
\text { Evans, Rhiannon; Oxford University, Chemistry } \\
\text { Hexter, Suzannah; Oxford University, Chemistry } \\
\text { Murphy, Bonnie; University of Oxford, Inorganic Chemsitry } \\
\text { Roessler, Maxie; Queen Mary University of London, Chemistry } \\
\text { Wulff, Philip; Oxford University, Chemistry }\end{array}$ \\
\hline
\end{tabular}

SCHOLARONE ${ }^{m}$

Manuscripts 


\title{
Guiding Principles of Hydrogenase Catalysis Instigated and Clarified by Protein Film Electrochemistry
}

\author{
Fraser A. Armstrong,* Rhiannon M. Evans, Suzannah V. Hexter, Bonnie J. Murphy, \\ Maxie M. Roessler and Philip Wulff \\ Department of Chemistry, University of Oxford, South Parks Road, \\ Oxford, OX1 3QR, UK \\ *To whom correspondence should be addressed: fraser.armstrong@chem.oc.ac.uk
}

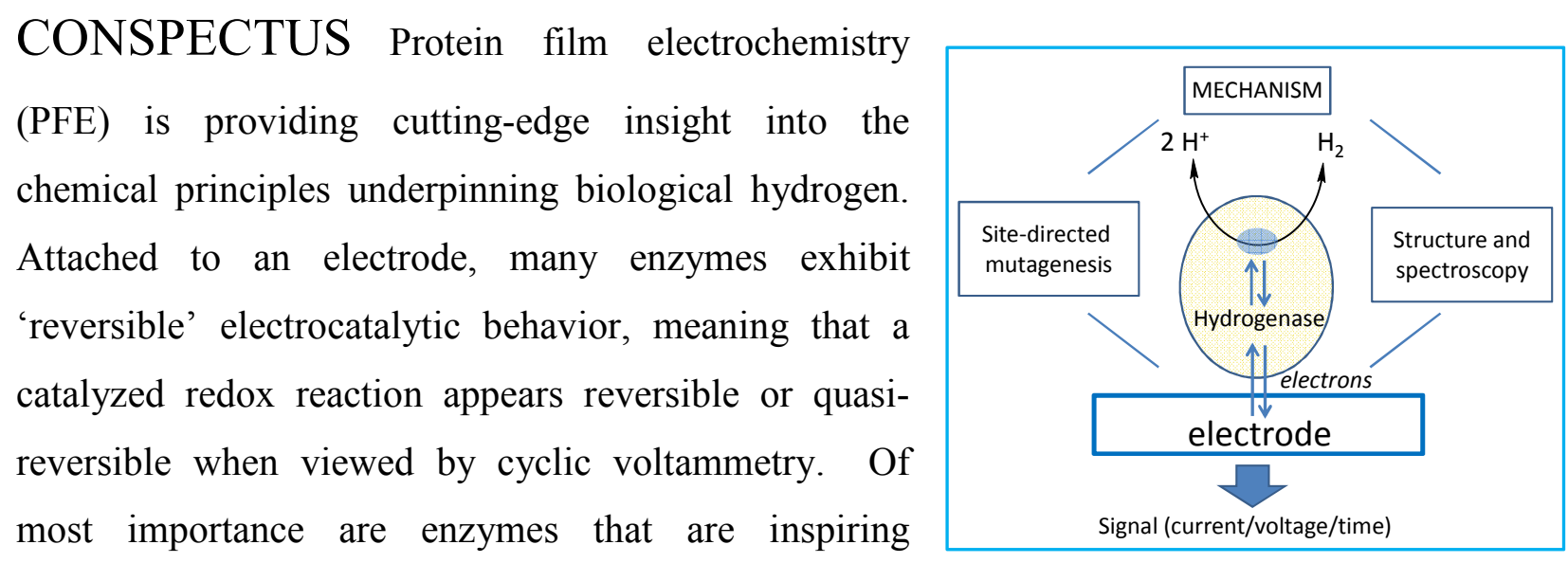
advances in renewable energy, such as Hydrogen-activating and $\mathrm{CO}_{2}$-reducing enzymes. Exploiting the rich repertoire of available instrumental methods, PFE experiments yield both a general snapshot and fine detail, all from tiny samples of enzyme. The dynamic electrochemical investigations trailblaze and add exquisite detail to the information gained from structural and spectroscopic studies. This Account describes recent investigations of hydrogenases carried out in Oxford, including ideas initiated with PFE and followed through with complementary techniques - all contributing to an eventual complete picture of fast and efficient $\mathrm{H}_{2}$ activation without Pt.

By immobilizing an enzyme on an electrode, catalytic electron flow and the chemistry controlling it can be addressed at the touch of a button. The buried nature of the active site means that structures that have been determined by crystallography or spectroscopy are likely to be protected, retained and fully relevant in a PFE experiment. An electrocatalysis model formulated 
for the PFE of immobilized enzymes predicts interesting behavior and gives insight into why some hydrogenases are $\mathrm{H}_{2}$ producers and others are $\mathrm{H}_{2}$ oxidizers. Immobilization also allows for easy addition and removal of inhibitors along with precise potential control, one interesting outcome being that formaldehyde forms a reversible complex with reduced [FeFe]-hydrogenases - thereby providing insight into the order of electron and proton transfers. Experiments on $\mathrm{O}_{2}$-tolerant $[\mathrm{NiFe}]$-hydrogenases show that $\mathrm{O}_{2}$ behaves like a reversible inhibitor: it is also a substrate, and implicit in the description of some hydrogenases as ' $\mathrm{H}_{2} / \mathrm{O}_{2}$ oxidoreductases' is the hypothesis that fast and efficient multi-electron transfer is a key to $\mathrm{O}_{2}$ tolerance because it promotes complete reduction of $\mathrm{O}_{2}$ to harmless water. Not only is a novel [4Fe-3S] cluster (able to transfer two electrons consecutively) an important component, but connections to additional electron sources - other Fe-S clusters, an electrode, another quaternary structure unit, or the physiological membrane itself - ensure that $\mathrm{H}_{2}$ oxidation can be sustained in the presence of $\mathrm{O}_{2}$, as demonstrated with enzyme fuel cells able to operate on $\mathrm{a}_{2}$ /air mixture.

Manipulating the $\mathrm{H}-\mathrm{H}$ bond in the active site is the simplest proton-coupled electrontransfer reaction to be catalyzed by an enzyme. Unlike small molecular catalysts or the surfaces of materials, metalloenzymes are far better suited to engineering the all-important outercoordination shell. Hence, recent successful site-directed mutagenesis of the conserved outershell 'canopy' residues in a [NiFe]-hydrogenase opens up new opportunities for understanding the mechanism of $\mathrm{H}_{2}$ activation beyond the role of the inner coordination shell.

\section{INTRODUCTION}

Overview. Evolutionary fine-tuning over two billion years produced $\mathrm{H}_{2}$-activating electrocatalysts rivalling platinum in efficiency and rate, but based on nickel and iron. Hydrogenases $^{1,2}$ exhibit turnover frequencies well exceeding $1000 \mathrm{~s}^{-1}$; hence, establishing the structural and mechanistic principles that yield such superb catalysts from common elements is important for realizing competitive solar-based renewable $\mathrm{H}_{2}$.

Figure 1 shows connections between electrocatalysis (A), physiology (B) and technology (C) of redox enzymes. Hydrogenases undergo numerous complex, entangled chemical transformations that are resolved by protein film electrochemistry (PFE), in which enzymes are connected directly to an electrode (Figure 1A), allowing their electrocatalytic properties to be addressed at the touch of a button. ${ }^{1}$ The electrode potential controls direction $\left(2 \mathrm{H}^{+}+2 \mathrm{e}^{-} \leftrightarrow \mathrm{H}_{2}\right)$ 
and rates of catalytic electron flow are reported directly as current. In biology, many redox enzymes are 'wired' to cellular redox processes; for example, membrane-bound hydrogenases (MBHs) transfer electrons to quinones. Panel B depicts how knallgas bacteria use $\mathrm{H}_{2}$ as an electron source and $\mathrm{O}_{2}$ as oxidant. Such inspirational enzymes are being used as electrocatalysts in fuel and solar cells (Figure 1C), and although isolated enzymes are unlikely to be useful in large-scale energy technology, such demonstrations highlight important possibilities, were catalysts as proficient as enzymes to become available. Enzyme fuel cells operate under ambient conditions without precious metals, and so-called ' $\mathrm{O}_{2}$-tolerant' hydrogenases generate power from safe $\mathrm{H}_{2} / \mathrm{O}_{2}$ mixtures without an expensive proton membrane. ${ }^{3-5}$

Using PFE alongside molecular biology, crystallography and spectroscopy, we have addressed some key questions in hydrogenase research. Normal spectroscopic methods, EPR and IR, focus on characterizing individual states: the value of PFE lies in complementing these techniques, to see first in snapshot, then detail, the underlying redox chemistry determining catalytic activity. Important instrumental techniques are cyclic voltammetry (CV), where the electrode potential is cycled, and chronoamperometry (CA), in which the potential is poised or stepped to different values. Excluding substrate mass transport, electrocatalysis has two components - interfacial (electrode-enzyme) electron transfer (ET, $k_{1}$ ) depending mainly on potential, and catalysis $\left(k_{2}\right)$ which depends on internal properties of the enzyme. ${ }^{6-8} \mathrm{~A} \mathrm{CV}$ resembles a spectrum where an observable (signal) is probed in the potential domain. In CA, steady-state catalysis is interrupted by potential steps or inhibitor injections to extract the kinetics of interconversions between different enzyme states. A rotating disc pyrolytic graphite 'edge' (PGE) electrode is commonly used, as many enzymes adsorb well, typically to give picomole $/ \mathrm{cm}^{2}$ electroactive coverage. Electrode rotation controls mass transport of small molecules, particularly dissolved gases introduced to the cell headspace by mass-flow controllers (MFCs).

\section{STRUCTURES OF HYDROGENASES}

Active sites. This Account focuses on the two major classes - [NiFe]-hydrogenases and $[\mathrm{FeFe}]$-hydrogenases. Although the protein structures are evolutionarily unrelated, the inner coordination shells of their catalytic centers, Figure 2, share important features. ${ }^{2,9}$ Hydrogen activation involves heterolytic cleavage via an arrangement of the type $\left[\mathrm{M}-\mathrm{H}^{-}---\mathrm{H}^{+}-\mathrm{B}\right]$ where 
base $\mathrm{B}$ is positioned for proton abstraction and transition metal $\mathrm{M}$ binds a hydrido ligand and releases $\mathrm{H}^{+}$upon two successive ETs. Oxidation and formation of $\mathrm{H}_{2}$ is the simplest of all enzyme reactions and the ordering and timing of events have fundamental importance.

The $[\mathrm{NiFe}]$-hydrogenase active site contains a bimetallic center in which a $\mathrm{Ni}$ accesses oxidation states $+1,+2$ and +3 , while the Fe appears to remain as +2 . $^{2}$ The metal atoms are anchored by four cysteines, two bridging the $\mathrm{Fe}$ and $\mathrm{Ni}$ and two bound terminally to the $\mathrm{Ni}$. The $\mathrm{Fe}$ is further coordinated by two $\mathrm{CN}^{-}$and one $\mathrm{CO} .{ }^{9}$ Depending on oxidation level, the space between $\mathrm{Ni}$ and Fe may be occupied by an exogenous ligand (' $\mathrm{X}$ ' in Figure $2 \mathrm{~A}$ is $\mathrm{H}^{-}$or $\mathrm{OH}^{-}$). The canopy above the space contains a strictly-conserved pendant arginine, and two strictly/highly-conserved aspartates, and recent studies have led to a new proposal for the $\mathrm{H}_{2}$ activation mechanism involving the arginine as catalytic base. ${ }^{10}$ If correct, the mechanism unites the fields of hydrogenases and the best functional analogues. ${ }^{11}$

The [FeFe]-hydrogenases contain an extended 6Fe active site known as the 'H-cluster' featuring a $[2 \mathrm{Fe}]$ subsite with two low-spin $\mathrm{Fe}$, each coordinated by $\mathrm{CN}^{-}$and $\mathrm{CO}$ ligands, positioned proximally $\left(\mathrm{Fe}_{\mathrm{p}}\right)$ and distally $\left(\mathrm{Fe}_{\mathrm{d}}\right)$ with respect to a [4Fe-4S] cluster that is connected to $\mathrm{Fe}_{\mathrm{p}}$ by a cysteine-S. ${ }^{2}$ The $\mathrm{Fe}_{\mathrm{p}}$ and $\mathrm{Fe}_{\mathrm{d}}$ atoms are linked by an azadithiolate $\left(\mathrm{SCH}_{2}(\mathrm{NH}) \mathrm{CH}_{2} \mathrm{~S}\right)$ ligand, in which the bridgehead $\mathrm{N}$-atom is proposed as the catalytic base. ${ }^{12}$

Long-range electron transfer. To see how hydrogenases can interact with electrodes, we refer to the structure (Figure 3) of Hydrogenase-1 (Hyd-1) from E.coli, which is a paradigm for $\mathrm{O}_{2}$-tolerant $[\mathrm{NiFe}]$-hydrogenases that are membrane-bound in vivo. ${ }^{13}$ The membraneextrinsic $(\alpha \beta)_{2}$ dimer contains the active site (located in $\alpha$ ) and three Fe-S clusters (located in $\beta$ ). The short distance between distal $[4 \mathrm{Fe}-4 \mathrm{~S}]_{\mathrm{D}}$ clusters suggests the possibility of ET between the two $\alpha \beta$ monomers. Electroactivity requires the most exposed Fe-S cluster $\left([4 \mathrm{Fe}-4 \mathrm{~S}]_{\mathrm{D}}\right)$ to approach the electrode closely. Contacts and coverage are greatly improved by modifying the electrode with carbon nanotubes ${ }^{4,14}$ - an important trick for fuel cells (yielding current densities $>1 \mathrm{~mA} \mathrm{~cm}^{-2}$ ) and for studying variants having very low activities.

\section{HYDROGENASES AS ELECTROCATALYSTS: FIRST}

\section{IMPRESSIONS}

The most efficient electrocatalysts operate reversibly, i.e. the current changes sign immediately either side of the equilibrium (zero current) potential ' $E_{\mathrm{eq}}$ ': this is indeed the case 
for most hydrogenases. ${ }^{15}$ Figure 4 shows representative CVs and known states of [NiFe]- and [FeFe]-hydrogenases that should prevail across different potential regions.

The CVs inform us immediately how rates of evolution or oxidation of $\mathrm{H}_{2}$ and sensitivity to inhibitors vary with electrode potential. Panel A shows results for Hyd-1 and Hyd-2 another E. coli $\mathrm{MBH}$. An obvious difference is that Hyd-2 catalyzes proton reduction whereas Hyd-1 appears not to (but see below). ${ }^{16}$ Panel B shows results for two [FeFe]-hydrogenases CrHydA1 from a green alga (Chlamydomonas reinhardtii) and CaHydA from a fermentative anaerobe (Clostridium acetobutylicum). Voltammograms for Hyd-2 and CaHydA cut through the zero-current axis at $E_{\text {eq }}$ for the $2 \mathrm{H}^{+} / \mathrm{H}_{2}$ couple under these conditions, hence electrocatalysis is 'reversible' near this value. The intersection is less sharply defined for $C r H y d A 1$, which lacks an Fe-S relay. ${ }^{7}$ Both Hyd-1 and Hyd-2 form an inactive Ni(III) state Ni-B (X $\left.=\mathrm{OH}^{-}\right)$at high potential, and although the hysteresis signifies kinetic restrictions, re-activation is rapid, hence $\mathrm{Ni}-\mathrm{B}$ is known as 'Ready'. ${ }^{2}$ Similar interconversions are observed with [FeFe]-hydrogenases: inactive states $\mathrm{H}_{\mathrm{ox}}$ inact are formed with $\mathrm{CrHydA1}$ (fast, almost reversible) and CaHydA (slow, more resistant to oxidative inactivation). ${ }^{17}$ Upon scanning in the negative direction, the inactive states are re-activated in processes marked empirically by a potential denoted $E_{\text {switch }}$, corresponding to an inflection point extracted from the first derivative. The potential window for $\mathrm{H}_{2}$ oxidation by these enzymes lies roughly between $E_{\text {switch }}$ and the catalytic onset potential. Despite its lower onset potential, the much more negative $E_{\text {switch }}$ value for Hyd-2 gives it a smaller window than Hyd-1. ${ }^{16}$

The voltammograms reveal the catalytic bias, although account must be taken of $\mathrm{H}_{2}$ affinity (Michaelis and inhibition constants) and partial pressure $\rho\left(\mathrm{H}_{2}\right)$. Compared to [FeFe]-hydrogenases, [NiFe]-hydrogenases usually have much lower values of $K_{\mathrm{M}}{ }^{\mathrm{H} 2}$ (oxidation) and $K_{\mathrm{I}}^{\mathrm{H} 2}\left(\mathrm{H}^{+}\right.$reduction). For [NiFe]-hydrogenases, decreasing $\rho\left(\mathrm{H}_{2}\right)$ from $100 \%$ to $1 \%$ usually causes only a modest drop in $\mathrm{H}_{2}$ oxidation current while the proton reduction current increases, whereas [FeFe]-hydrogenases show a large decrease in $\mathrm{H}_{2}$ oxidation current and little enhancement in proton reduction. ${ }^{18}$

Figure 4C includes an intermediate, 'Ni-L', long regarded as an artifact of illuminating Ni-C at low temperature. ${ }^{19}$ Whereas Ni-C is formulated as a $\mathrm{Ni}(\mathrm{III})$ hydrido species $\left(\mathrm{X}=\mathrm{H}^{-}\right)$in Figure $2 \mathrm{~A}, \mathrm{Ni}-\mathrm{L}$ is assigned as a $\mathrm{Ni}(\mathrm{I})$ species $-\mathrm{H}^{-}$having migrated as $\mathrm{H}^{+}\left[\mathrm{ref}{ }^{2}\right]$. In recent developments that may prove mechanistically significant, in situ protein film IR experiments 
with Hyd-1 demonstrated that Ni-L is the major species during steady-state electrochemical $\mathrm{H}_{2}$ oxidation, ${ }^{20}$ while EPR and IR studies revealed that $\mathrm{Ni}-\mathrm{L}$ and $\mathrm{Ni}-\mathrm{C}$ interconvert with $\mathrm{pH} .{ }^{19}$

\section{INTERPRETING ELECTROCATALYSIS BY HYDROGENASES}

Modeling enzyme electrocatalysis. A model developed for interpreting catalytic voltammograms for immobilized enzymes ${ }^{6,7}$ exploits the logical requirement that at any given electrode potential a true catalyst possesses no inherent bias to favor a particular direction, beyond that dictated by thermodynamics alone.

There are two levels to the model, shown in Scheme 1. The basic level assumes: (1) the substrate concentration is sufficiently high to saturate the binding site (hence focusing on electron flow within the enzyme-substrate complex); (2) the enzyme exists in a single Form (Form I) over the whole potential range. Interfacial ETs (see Figure 1A) are termed $k_{1 \mathrm{a}}$ or $k_{1 \mathrm{c}}$ depending on direction (anodic or cathodic) while intramolecular ET and catalytic turnover are combined within $k_{2 \mathrm{a}}$ or $k_{2 \mathrm{c}}{ }^{7}$ Interfacial ET occurs at the electron entry/exit site with reduction potential $E_{\text {ox/red. }}$. The catalytic bias (here, the tendency of the substrate-saturated enzyme to operate preferentially in a particular direction) is predicted by Equation 1,

$$
\text { bias }=\frac{k_{2 \mathrm{c}}}{k_{2 \mathrm{a}}}=\exp \left[-\frac{n F}{R T}\left(E_{\mathrm{ox} / \mathrm{red}}^{0}-E_{\mathrm{eq}}\right)\right]
$$

where $n$ is the overall number of electrons involved and $E_{\text {eq }}$ is the equilibrium potential imposed by oxidized and reduced substrate. ${ }^{7}$ The model highlights the role of the distal $[4 \mathrm{Fe}-4 \mathrm{~S}]_{\mathrm{D}}$ cluster as the electrochemical control center ${ }^{8}$ since this site is the most likely electron entry/exit point and determinant of $E_{\mathrm{ox} / \mathrm{red}}$. The catalytic bias depends on the difference between $E_{\mathrm{ox} / \mathrm{red}}$ and $E_{\mathrm{eq}}-$ similar values minimize the bias so the electrocatalyst behaves reversibly near $E_{\text {eq. }}$ The potential-dependent rate of interfacial (electrode-enzyme) ET is modeled with Butler-Volmer kinetics, whereas the overall rate constant covering intramolecular ET and catalysis is assumed to be potential-independent.

The second level of the model includes potential-dependent interconversions that change the overall activity of the enzyme. ${ }^{6}$ Form II may bind substrate or inhibitors with different affinity to Form I, or may be completely inactive (a resting state). When rate constants $k_{3}$ are high in each direction, interconversion becomes Nernstian with potential $E_{3}$. We consider these 
interconversions later, but we first show how the basic model explains why some hydrogenases appear to operate exclusively in the 'Uptake' (oxidation) direction. ${ }^{21}$

The role of ET in catalytic bias. Membrane-bound $\mathrm{O}_{2}$-tolerant hydrogenases exhibit a significant 'onset' overpotential requirement for $\mathrm{H}_{2}$ oxidation and little or no $\mathrm{H}_{2}$ production activity (Figure $4 \mathrm{~A})^{7,16}$. Although strong product inhibition is one factor, no proton reduction appears under $100 \%$ Ar. The inability to produce $\mathrm{H}_{2}$ is explained by Equation 1 if the reduction potential $\left(E_{\mathrm{ox} / \mathrm{red}}\right)$ of the distal cluster $[4 \mathrm{Fe}-4 \mathrm{~S}]_{\mathrm{D}}>>E_{\mathrm{eq}}$. The voltammogram in Figure $4 \mathrm{~A}$ was measured at $\mathrm{pH}$ 6: whereas $E_{\text {eq }}$ varies by $-60 \mathrm{mV} / \mathrm{pH}$ unit, the $\mathrm{pH}$ dependence of Fe-S potentials is usually much less, and it was thus predicted that Hyd-1 should become a reversible electrocatalyst as the $\mathrm{pH}$ is lowered to close the gap $\left(E_{\mathrm{ox} / \mathrm{red}}-E_{\mathrm{eq}}\right)$. This prediction was borne out. $^{21}$ The onset potential is insensitive to $\rho\left(\mathrm{H}_{2}\right)$ but shifts in a positive directions as the $\mathrm{pH}$ is lowered, and reversibility is achieved at $\mathrm{pH}$ 3. The substantial $\mathrm{H}_{2}$ production activity (Figure $5 \mathrm{~A}$ ) increases further upon changing to $100 \%$ Ar to minimize product inhibition (Figure $5 \mathrm{~B}$ ). The importance of a rotating disc electrode is immediately apparent, since the $\mathrm{H}^{+}$reduction current is much higher at $2000 \mathrm{rpm}$ than under stationary conditions. Rotating the electrode sweeps away the inhibitory $\mathrm{H}_{2}$ product: equally, the analogous experiment at $0 \mathrm{rpm}$ confirms that $\mathrm{H}_{2}$ is the product, revealing it as a sharp peak due to depletive oxidation.

That catalytic bias depends on the potential of the center where electrons enter or leave the enzyme is no surprise: it applies wherever ET occurs via soluble mediators, additional subunits ${ }^{18}$ or the quinone pool of a membrane. ${ }^{22}$

Potential dependence of Steady-state species. Further subtle properties are revealed through the potential dependence and explained using the second level of the model. Unlike reduction potentials extracted from static redox titrations, potentials in electrocatalytic PFE refer to steady-state conditions, although hysteresis in CVs indicates that interconversions between different species (such as Forms I and II in Scheme 1) have slow components. Catalytic bias can result if a more active Form dominates in a potential region favoring a particular direction.

Rapid reductive reactivation of $\mathrm{Ni}-\mathrm{B}$ is important in allowing certain [NiFe]-hydrogenases to be $\mathrm{O}_{2}$ tolerant. Interconversion between active enzyme (Form I) and inactive Ni-B (Form II) exemplifies the extended model. In Scheme 1, interconversion is modeled using a potential $E_{3}$. The marker $E_{\text {switch }}$ relates somehow to the reduction potential for the Ni-B/Ni-SI couple, ${ }^{1}$ (where Ni-SI refers to the most oxidized active state of the catalytic cycle) but as emphasized by Léger, $E_{\text {switch }}$ is best regarded only as an empirical guide to the ease 
with which Ni-B is activated. ${ }^{23}$ Not only is $E_{\text {switch }}$ not an equilibrium property (the reduced states cycle rapidly) but other factors are relevant, for example, $E_{\text {switch }}$ is sensitive to the potential dependence of the ascending $\mathrm{H}_{2}$ oxidation.

There is an interesting analogy with passivation of Pt-metal catalysts, where $\mathrm{H}_{2}$ oxidation is blocked by an oxide layer. ${ }^{6}$ Figure $6 \mathrm{~A}$ compares $2 \mathrm{H}^{+} / \mathrm{H}_{2}$ electrocatalysis by Hyd-2 adsorbed on PGE and by a Ru electrode, in each case scaled to the Reversible Hydrogen Electrode (RHE). Correspondence between $E_{\text {switch }}$ (the observable) and $E_{3}$ depends on the steepness of the potential dependence for $\mathrm{H}_{2}$ oxidation: the $\mathrm{Ru}$ data could be fitted with $E_{3}$ as low as $+0.05 \mathrm{~V}$, i.e. on the ascending side of the peak and clearly far more negative than $E_{\text {switch. Moreover, an enzyme }}$ (Form II being inactive) for which $E_{3}$ lies below the $2 \mathrm{H}^{+} / \mathrm{H}_{2}$ potential should be strongly biased toward $\mathrm{H}_{2}$ evolution.

Figure 6B shows voltammograms comparing reactivation of Ni-B in native Hyd-1 and variants in which strictly and highly conserved residues of the active-site canopy (Figure 2A) have been mutated. ${ }^{10}$ The shapes (voltammograms are normalized to peak activity) reflect how mutations alter the active-site environment, independently of variations in catalytic rate. Changing Arginine 509 to Lysine (attempting to preserve electrostatics) lowers activity $>100$ fold, yet the reactivation characteristics are unchanged (native and R509K voltammograms overlay). In contrast, charge-neutralizing variants D118A (26\% activity), D574N (86\%) and D118N/D574N (20\%) stabilize Ni-B (possibly by enhancing the local availability of $\mathrm{OH}^{-}$), yielding increasingly narrow activity windows because the onset potential remains unchanged.

Michaelis constants for $\mathrm{H}_{2}$ oxidation are determined from the $\mathrm{CV}$ currents at different potentials for various $\rho\left(\mathrm{H}_{2}\right)$. For Hyd- $1, K_{\mathrm{M}}{ }^{\mathrm{H} 2}$ at $\mathrm{pH} 6$ increases five-fold from -0.25 to $+0.10 \mathrm{~V}$ (Figure 6C) - a fact that might reflect a change in the dominant catalytic species as the potential is raised, but is more likely due to the fact that $K_{\mathrm{M}}{ }^{\mathrm{H} 2}=\left(k_{\text {cat }}+k_{\text {off }}\right) / k_{\text {on }}$, where $k_{\text {on }}$ and $k_{\text {off }}$ refer to $\mathrm{H}_{2}$ binding and dissociation and $k_{\mathrm{cat}}$ is the net turnover frequency based on all elementary steps. These steps include interfacial ET; hence $k_{\text {cat }}$ should increase with potential and it is no surprise that $K_{\mathrm{M}}{ }^{\mathrm{H} 2}$ also increases. The potential dependence of $K_{\mathrm{M}}{ }^{24}$ is rarely encountered in conventional experiments because it is difficult to vary the thermodynamic driving force systematically. The Michaelis complex $\mathrm{E}-\mathrm{H}_{2}$ is probably very short lived.

How inhibitors target particular intermediates. Experiments on $[\mathrm{FeFe}]$-hydrogenases show how inhibitors selectively target intermediates. For example, CVs of CaHydA and 
CrHydA1 (Figure 4B) are affected very differently by carbon monoxide and formaldehyde (HCHO) depending on the potential being applied. The effects are best analyzed by constant potential chronoamperometry. ${ }^{17,25}$ Carbon monoxide levels are controlled by MFCs, whereas formaldehyde is injected as concentrated aliquots and removed by replacing the entire solution with fresh electrolyte (the latter feature emphasizes the importance of enzyme immobilization). Figure 6D shows how the rapid current attenuations observed by CA upon introducing $\mathrm{HCHO}$ or CO to $C a$ HydA depend on potential. ${ }^{25}$ Both curves are fitted to two one-electron Nernst functions that are roughly complementary for $\mathrm{HCHO}$ and $\mathrm{CO}$. Under oxidizing conditions where $\mathrm{H}_{\mathrm{ox}}$ should dominate, the hydrogenase undergoes almost complete inactivation when exposed to $\mathrm{CO}$, whereas $\mathrm{HCHO}$ has little effect. The opposite is true under highly reducing conditions: a state two electrons more reduced than $\mathrm{H}_{\mathrm{ox}}$ has little affinity for $\mathrm{CO}$ but reacts strongly with HCHO. Based on the reversibility of HCHO inhibition, DFT calculations, and ENDOR spectra of $\mathrm{CrHydA} 1$ reduced by $\mathrm{H}_{2}$ in the presence of $\mathrm{H}^{13} \mathrm{CHO}$, it was proposed that $\mathrm{HCHO}$ intercepts a transient intermediate at the same oxidation level as $\mathrm{H}_{\text {sred }}$ (see Figure 4C), forming a trapped species with a carbanionic $\mathrm{Fe}_{\mathrm{d}} \mathrm{C}$ bond and a H-bond to protonated bridgehead-N (Species 1). ${ }^{26}$ Electrophilic $\mathrm{HCHO}$ competes with proton transfer to the electron-rich $\mathrm{Fe}_{\mathrm{d}}$ site whereas $\pi$ acceptor $\mathrm{CO}$ competes with $\mathrm{H}_{2}$ binding to the most oxidized active state.

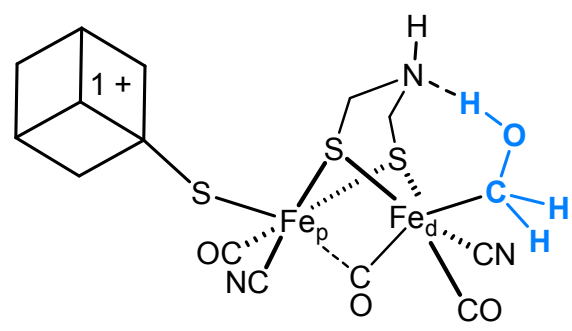

\section{Species 1- Proposed formaldehyde-trapped H-cluster intermediate}

\section{DEFINING AND INVESTIGATING O ${ }_{2}$ TOLERANCE}

It has long been known that hydrogenases are inactivated by $\mathrm{O}_{2}{ }^{1,2}$ In general, $[\mathrm{NiFe}]$-hydrogenases fare much better than [FeFe]-hydrogenases, for which even traces of $\mathrm{O}_{2}$ cause irreversible damage: moreover, $\mathrm{O}_{2}$-tolerant $[\mathrm{NiFe}]$-hydrogenases sustain activity under aerobic conditions. ${ }^{24,27}$ Understanding how $\mathrm{O}_{2}$ attacks and how to avoid damage are important goals if these enzymes and their organisms are to be exploited in technology. Earlier research 
focused on the role of internal gas channels in stemming $\mathrm{O}_{2}$ transport to the active site without affecting passage of $\mathrm{H}_{2}$. ${ }^{9}$ With its ability to control and measure simultaneously, PFE has been crucial in showing the importance of long-range ET in $\mathrm{O}_{2}$ tolerance.

How [NiFe]-hydrogenases survive $\mathbf{O}_{2}$ attack. Even if inactivation of $[\mathrm{FeFe}]$-hydrogenases by $\mathrm{O}_{2}{ }^{17,28,29}$ is partly reversible - as reported by Léger, ${ }^{30}$ sustaining longterm activity is questionable. In contrast, $\mathrm{O}_{2}$ attacks [NiFe]-hydrogenases to form an easily recoverable inactive state. One key point of the model ${ }^{24}$ in Scheme 2 is that the desired product of $\mathrm{O}_{2}$ attack is Ni-B (Ready), which is rapidly reactivated by one-electron reduction (the process

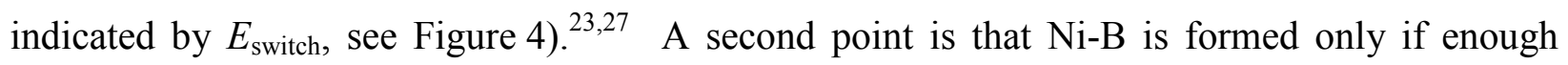
electrons are immediately available to avoid formation of reactive oxygen intermediates that produce the 'Unready' state (Ni-A). In addition to a $\mathrm{OH}^{-}$ligand, Unready has less tractable cysteine S-O modification $^{10,31}$ which removes it from the catalyst pool; thus [NiFe]hydrogenases must catalyze rapid four-electron $\mathrm{O}_{2}$ reduction with $100 \%$ fidelity to sustain $\mathrm{H}_{2}$ oxidation in the presence of $\mathrm{O}_{2}{ }^{27,32}$

Role of Fe-S clusters in $\mathbf{O}_{2}$ tolerance. Figure 7A shows CA experiments on Hyd-1 and Fe-S variants. The control experiment on native Hyd-1 starts with $100 \% \mathrm{H}_{2}$ : after establishing the stability trendline, the gas supply is switched to $10 \% \mathrm{H}_{2} / 90 \% \mathrm{Ar}$, which causes the current to drop to $70 \%$ of the original value. Then $\mathrm{O}_{2}$ is introduced in increments of $1 \%, 4 \%, 10 \%$, each time establishing a new steady current level, and the sequence is reversed. The final current at $100 \% \mathrm{H}_{2}$ is $>80 \%$ of the initial value, within the range expected from the trendline over 4500 seconds. In contrast, the $\mathrm{P} 242 \mathrm{C}$ variant in which the medial $[3 \mathrm{Fe}-4 \mathrm{~S}]_{\mathrm{M}}$ cluster has been converted to $\left[4 \mathrm{Fe}-4 \mathrm{~S}\right.$ ] fails under just $1 \% \mathrm{O}_{2}$, showing a continuous decrease in activity that is only $20 \%$ recovered when $100 \% \mathrm{H}_{2}$ is restored. ${ }^{27}$ The $\mathrm{C} 19 \mathrm{G}$ variant in which the unusual proximal $[4 \mathrm{Fe}-3 \mathrm{~S}]_{\mathrm{P}}$ cluster (conserved in many $\mathrm{O}_{2}$-tolerant membrane-bound [NiFe]hydrogenases) is replaced by [4Fe-4S] fares even worse, as the current under $1 \% \mathrm{O}_{2}$ rapidly drops to zero and there is negligible recovery when $100 \% \mathrm{H}_{2}$ is restored. ${ }^{32}$

The effect of $\mathrm{O}_{2}$ on Hyd-1 resembles reversible inhibition. From Scheme 2, if only Ni-B is produced, the fractional steady-state activity $f$ at each $\mathrm{O}_{2}$ concentration is given by Eq. 2

$$
f=\frac{\text { rate }_{\mathrm{A}}}{\text { rate }_{\mathrm{A}}+\text { rate }_{\mathrm{I}}}
$$


where rate $_{\mathrm{I}}$ and rate $_{\mathrm{A}}$ are inactivation and reactivation rates. Inactivation rates were measured from $\mathrm{CA}$ transients generated by injecting $\mathrm{O}_{2}$-saturated solutions. Fast reductive reactivation was investigated at different potentials and low temperatures using potential-step CA, and results were extrapolated to various conditions using the Arrhenius and Tafel relationships. ${ }^{27}$ Values of rate $_{\mathrm{I}}$ are potential-independent but depend directly on $\rho \mathrm{O}_{2}$, whereas rate $e_{\mathrm{A}}$ depends on potential but not $\rho \mathrm{O}_{2}{ }^{23,27}$ Thus $f$ decreases with $\rho \mathrm{O}_{2}$ and increasing potential. Good agreement was found between observed $f$ values and those calculated from elementary kinetics; for example, $f$ at $10 \%$ $\mathrm{O}_{2} / 10 \% \mathrm{H}_{2}$ is calculated and found experimentally to be 0.3 .

Isotope ratio mass spectrometry showed that Hyd- 1 converts ${ }^{18} \mathrm{O}_{2}$ almost exclusively to $\mathrm{H}_{2}{ }^{18} \mathrm{O}$ under a $\mathrm{H}_{2}$ atmosphere. ${ }^{33}$ Native enzyme accumulates $\mathrm{H}_{2}{ }^{18} \mathrm{O}$ under $90 \% \mathrm{H}_{2} / 10 \%{ }^{18} \mathrm{O}_{2}$ with a rate constant of ca. $0.65 \mathrm{~s}^{-1}$ without significant loss of activity (Figure 7B): in contrast, P242C quickly ceases to produce $\mathrm{H}_{2}{ }^{18} \mathrm{O}$. Membrane-bound, $\mathrm{O}_{2}$-tolerant [NiFe]-hydrogenases are therefore ' $\mathrm{H}_{2} / \mathrm{O}_{2}$-oxidoreductases'.

The behavior of $\mathrm{Fe}-\mathrm{S}$ variants proves the importance of remote ET for $\mathrm{O}_{2}$ tolerance. In P242C, the medial $[3 \mathrm{Fe}-4 \mathrm{~S}]_{\mathrm{M}}$ cluster $\left(+190 \mathrm{mV}^{34}\right)$ is replaced by a $[4 \mathrm{Fe}-4 \mathrm{~S}]$ cluster with lower reduction potential and correspondingly shorter electron residence time during catalytic electron flow. Notably, $\mathrm{H}_{2}$ oxidation activity, as well as $E_{\text {switch }}$ and rate $_{\mathrm{A}}$ are essentially unaffected for P242C. ${ }^{27}$ The difference is that $\mathrm{P} 242 \mathrm{C}$ accumulates Unready/Ni-A upon reaction with $\mathrm{O}_{2}$, whereas native Hyd-1 exhibits high fidelity for Ni-B formation. The unusual [4Fe-3S $]_{\mathrm{P}}$ center plays an important role in $\mathrm{O}_{2}$ tolerance through its ability to undergo two consecutive ETs over a small $(\leq 200 \mathrm{mV}$ ) potential range (Figure 8$){ }^{2,34}$ Simplistically, the high-potential redox couple conserves local electroneutrality through coordination by deprotonated amide $\left(\mathrm{N}_{\mathrm{C} 20}\right.$ in Hyd-1) in the highest oxidation level, i.e. it is a proton-coupled ET. ${ }^{2,13}$ From HYSCORE, the ${ }^{\text {peptide }} \mathrm{N}$-coordinated $\mathrm{Fe}$ has a localized $3+$ valence $^{34}$ - consistent with deprotonated amide-N being a strong $\pi$-donor. When $\mathrm{O}_{2}$ attacks, rapid transfer of two electrons from $[4 \mathrm{Fe}-3 \mathrm{~S}]_{\mathrm{P}}$, along with a third from $[3 \mathrm{Fe}-4 \mathrm{~S}]_{\mathrm{M}}$ and a fourth from $\mathrm{Ni}$ oxidation (forming $\mathrm{Ni}-\mathrm{B}$ as $\mathrm{Ni}(\mathrm{III})-\mathrm{OH}$ ) ensures that all electrons needed to convert $\mathrm{O}_{2}$ to $2 \mathrm{H}_{2} \mathrm{O}$ are quickly available, regardless of the oxidation level of the active site at the point of attack. The high fidelity necessary to ensure $\mathrm{O}_{2}$ tolerance is only apparent from extended CA measurements ${ }^{27}$ because simply injecting $\mathrm{O}_{2}$ during a CV fails to detect Ni-A accumulation..$^{27,32}$ Only once fidelity is established does gas channel 
engineering become useful, not to avoid formation of the Unready state but to increase $f$ by retarding rate . This fact is also clear from studies comparing the $\mathrm{O}_{2}$ tolerance of Hyd-1 and Hyd-2 deeply embedded in a porous electrode. By restricting access of $\mathrm{O}_{2}$ in this way, both Hyd1 and Hyd-2 exhibit higher fractional activity, but Hyd-2 fails upon prolonged exposure. ${ }^{3}$

Insights from fuel cell experiments. The $\mathrm{O}_{2}$-tolerant hydrogenases make possible simple, membrane-less fuel cells able to use non-explosive $\mathrm{H}_{2} / \mathrm{O}_{2}$ mixtures (Figure 1C). Hydrogenase- 1 can be used as the $\mathrm{H}_{2}$-oxidizing anode catalyst and bilirubin oxidase, a blue $\mathrm{Cu}$ oxidase, is used at the $\mathrm{O}_{2}$-reducing cathode (Figure 9). Power is measured by applying a variable resistor (load) across the electrodes and recording the voltage V. Performance improvements (modifying electrodes to increase enzyme coverage and stability) have yielded power densities above $1 \mathrm{~mW} / \mathrm{cm}^{2}$ (total electrode area). ${ }^{3-5}$ The interesting observation here is that under $\mathrm{H}_{2}$-weak conditions, the fuel cell loses power irreversibly when the load is small and V collapses. Realizing that the cell fails because Ni-B has formed without an electron source to reactivate it, power was restored by momentarily connecting a second anode loaded with active Hyd-1 to the original anode..$^{5}$ This 'jump start' demonstration suggested that quaternary structure is important in $\mathrm{O}_{2}$ tolerance, since the dimeric structure of Hyd-1 (Figure 3) may allow ET between the two halves. ${ }^{35}$ Consquently, Ni-B formed through $\mathrm{O}_{2}$ attack at one site might be reactivated by electrons originating in the still-functioning active site of the other $\alpha \beta$ half. Intra-dimer ET could be faster than drawing electrons from the electrode. This hypothesis was tested by comparing dimeric and monomeric forms of Hyd- $1 .^{36}$

Monomeric Hyd-1 was obtained by digitonin treatment and size-exclusion chromatography, and the $\mathrm{O}_{2}$ tolerance of dimeric and monomeric forms was compared. Figure 10A shows CA results at $10 \% \mathrm{O}_{2}$. The monomer is much more sensitive to $\mathrm{O}_{2}$ than native dimer, indeed the current soon drops to zero; yet upon returning to $100 \% \mathrm{H}_{2}$, both forms recover almost all their activity spontaneously. Hence neither form produces Unready, but $f$ is much smaller for monomer. Advantageously, fast electron exchange between the distal $[4 \mathrm{Fe}-4 \mathrm{~S}]_{\mathrm{D}}$ clusters makes available electrons generated by catalysis in the active half of the molecule (Figure 10B). Extending this conjecture, Jeuken's group demonstrated that the $\mathrm{O}_{2}$ tolerance of $[\mathrm{NiFe}]-\mathrm{MBH}$ from Ralstonia eutropha is increased further upon immobilization in a quinol-rich bilayer above an electrode. ${ }^{22}$ The fact that fully intact enzyme in a membrane environment offers the best protection suggests that PFE experiments are not so far removed from physiological reality. 


\section{ACKNOWLEDGEMENTS}

Research has been supported by grants BB/H003878-1, BB/I022309-1, BB/L009722-1, EP/D044855D and EP/H019480/1. Many colleagues have contributed, particularly Alison Parkin, Kylie Vincent, Bärbel Friedrich, Oliver Lenz, Michael Lukey, Thomas Happe, Frank Sargent, Annemarie Wait, Carina Foster, Thomas Esterle, Lang Xu, Andreas Bachmeier, and Emily Brooke. FAA is a Royal Society Wolfson Research Merit Award holder.

\section{BIOGRAPHICAL INFORMATION}

Fraser Armstrong is a Professor of Chemistry at Oxford University. He was awarded his PhD in 1978 from the University of Leeds.

Rhiannon Evans was awarded her PhD in 2010 from Cardiff University and is currently a post doctoral research associate at Oxford University.

Suzannah Hexter was awarded her DPhil in 2014 from Oxford University and currently works for AFC Energy, Surrey, UK.

Bonnie Murphy was awarded her DPhil in 2013 from Oxford University and is currently a post doctoral research associate at the Max-Planck-Institute for Biophysics, Frankfurt, Germany.

Maxie Roessler was awarded her DPhil in 2012 from Oxford University and is currently a Lecturer in Chemistry and Biochemistry at Queen Mary University, London.

Philip Wulff was awarded his DPhil in 2014 from Oxford University and is married to Bonnie Murphy. 


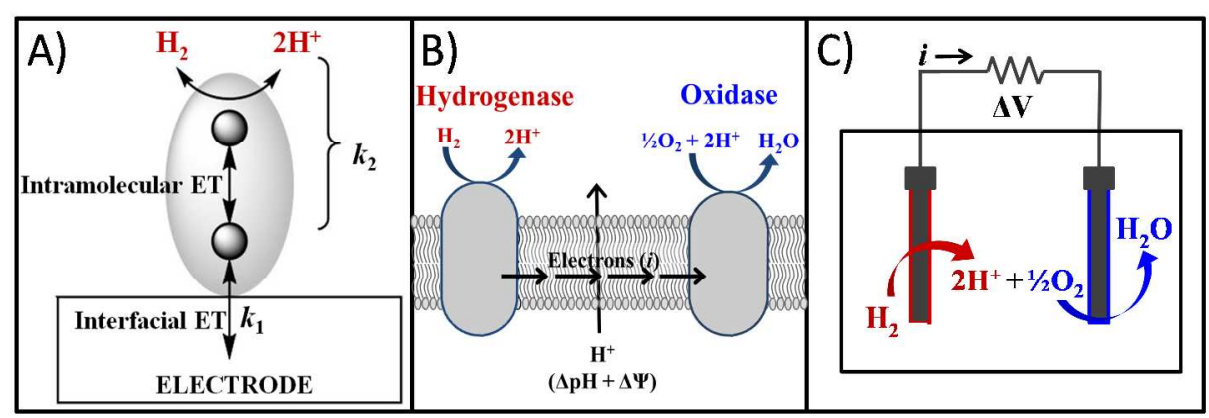

Figure 1: Electron-transport enzymes in electrocatalysis, biology and technology. A) Catalytic electron flow through an enzyme on an electrode. B) Aerobic $\mathrm{H}_{2}$ respiration: electrons from $\mathrm{H}_{2}$ oxidation by a membrane-bound $\mathrm{O}_{2}$-tolerant hydrogenase transfer (via quinols/cytochromes) to an oxidase. Electron transport (current, $i$ ) from hydrogenase to oxidase drives proton transfer, thus a 'load' is applied and work is done. C) Enzymatic fuel cell using hydrogenase and oxidase.

A

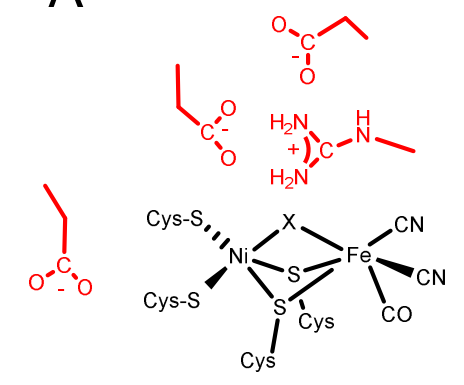

B

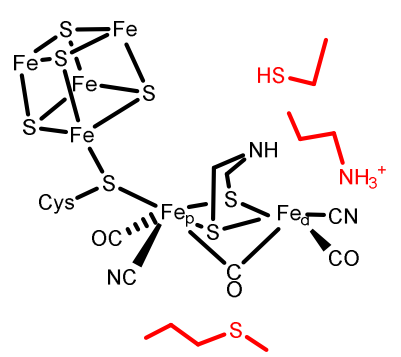

Figure 2: Active site representations of (A) [NiFe]-hydrogenases and (B) [FeFe]-hydrogenases. Outer-shell groups throught to be important for catalysis are shown in red.

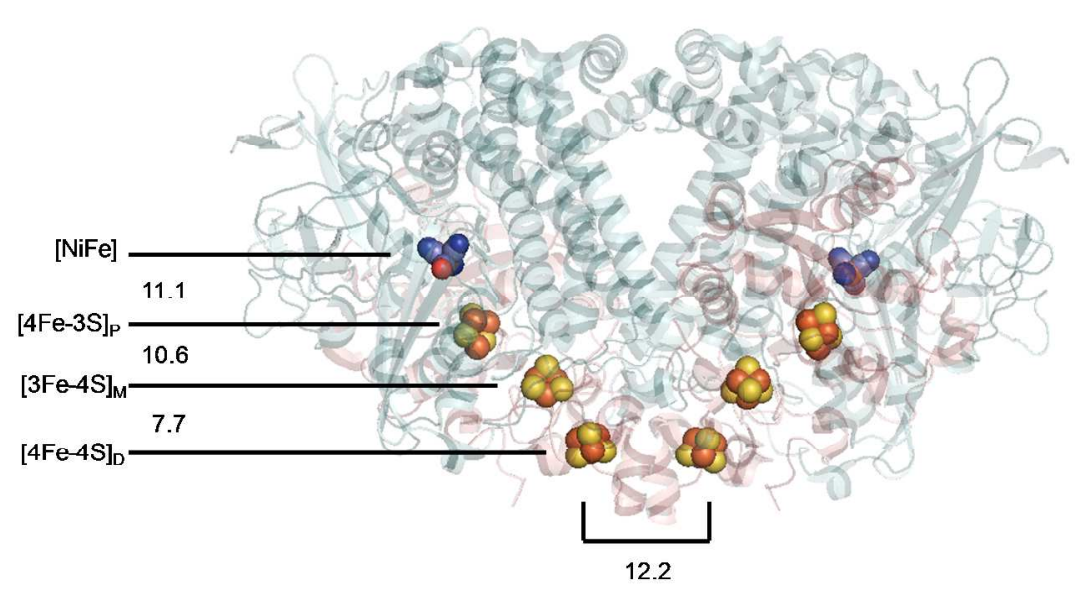

Figure 3. Structure (3UQY) of Hydrogenase-1. Numbers refer to inter-site distances ( $\AA$ ). Subscripts P, M, D refer to proximal, medial and distal with respect to the active site. Blue and pink ribbons represent $\alpha$ and $\beta$ subunits respectively. 


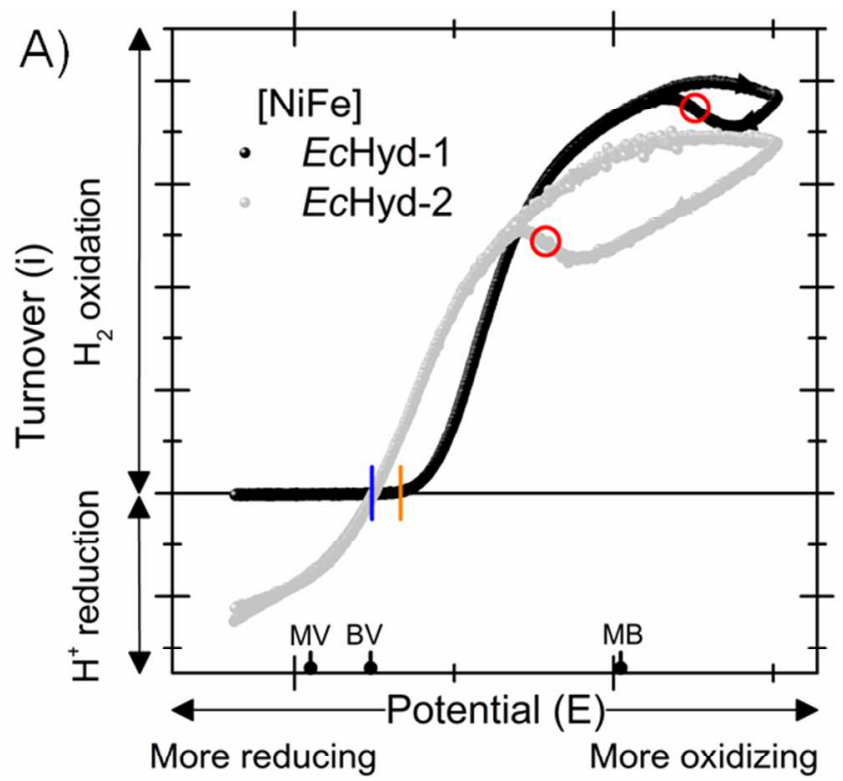

B)

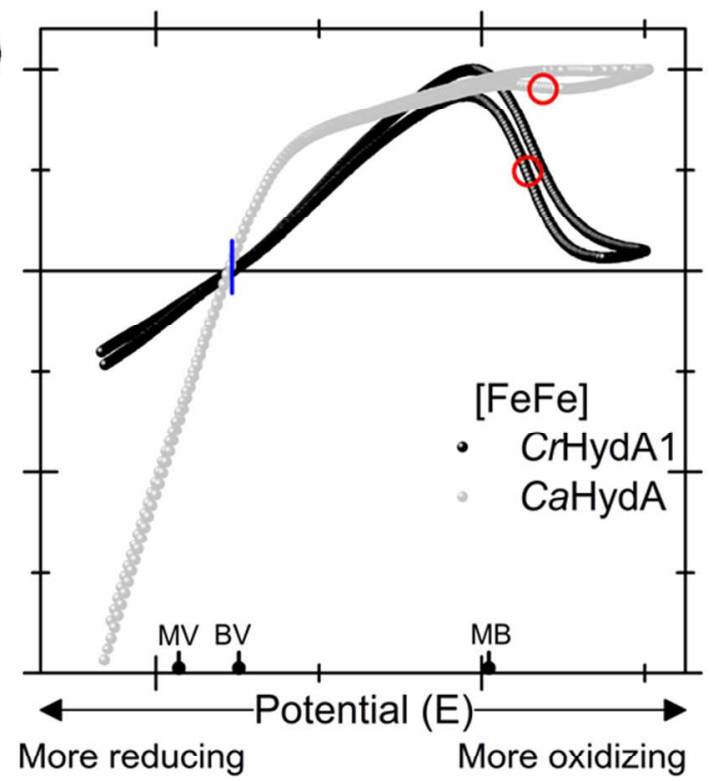

C)
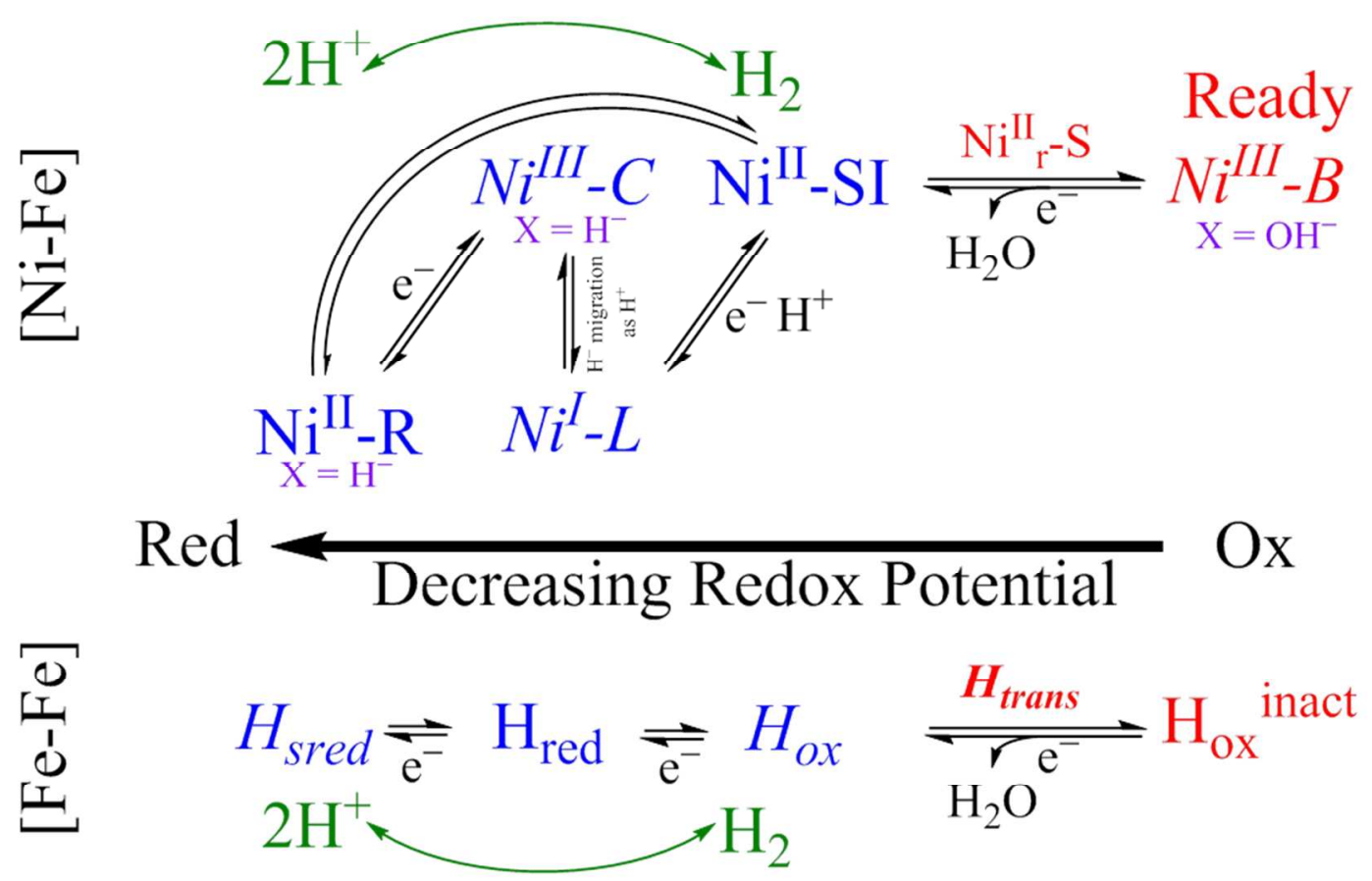

Figure 4: Electrocatalytic CVs of hydrogenases adsorbed on a PGE electrode. A. [NiFe]-hydrogenases Hyd-1 and $\mathrm{Hyd}-2$ at $10 \% \mathrm{H}_{2}, \mathrm{pH} 6,30{ }^{\circ} \mathrm{C}$, scan rate $=1 \mathrm{mV} / \mathrm{s}$. B. [FeFe]-hydrogenases ' $\mathrm{CrHydA1}$ ' and ' $\mathrm{CaHydA}$ ' at $100 \%$ $\mathrm{H}_{2}, \mathrm{pH} 6,20^{\circ} \mathrm{C}$, scan rate $=5 \mathrm{mV} / \mathrm{s}$. Corresponding reduction potentials of methyl viologen (MV), benzyl viologen (BV) and methylene blue (MB) are marked. Switch potentials $E_{\text {switch }}$ (red circles), equilibrium $2 \mathrm{H}^{+} / \mathrm{H}_{2}$ potential (blue lines) and the onset overpotential for $\mathrm{H}_{2}$ oxidation by Hyd-1 (orange line) are indicated. C. Dominant states of both enzymes arranged in order of oxidation level. EPR-active states are shown in italics. Notations $\mathrm{X}=\mathrm{OH}^{-}$or $\mathrm{H}^{-}$see Figure 2A. 

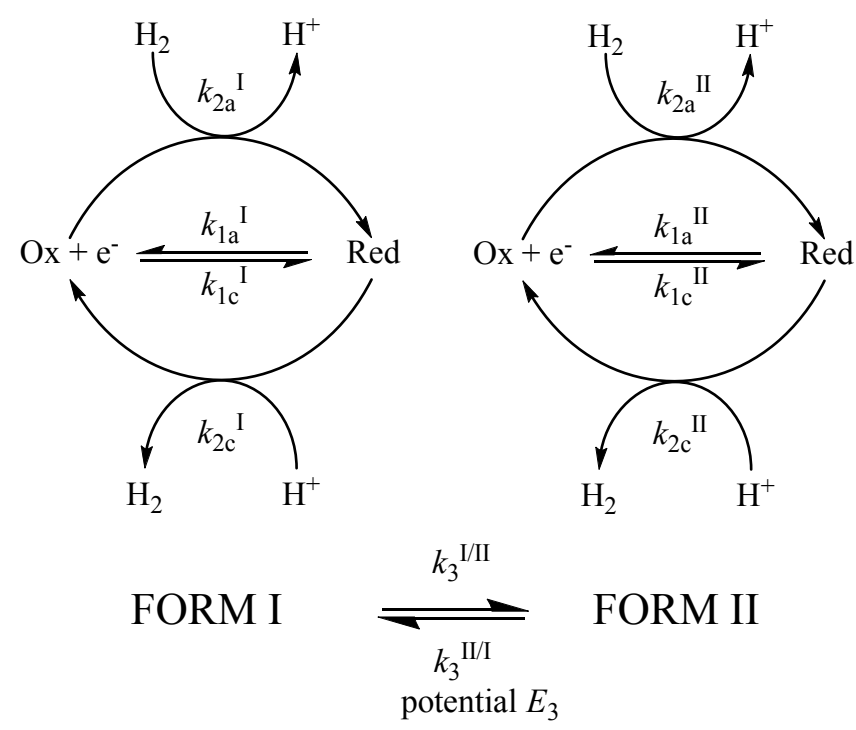

Scheme 1. Model for electrocatalysis by an enzyme attached to an electrode. The enzyme reaction is not limited by substrate binding.
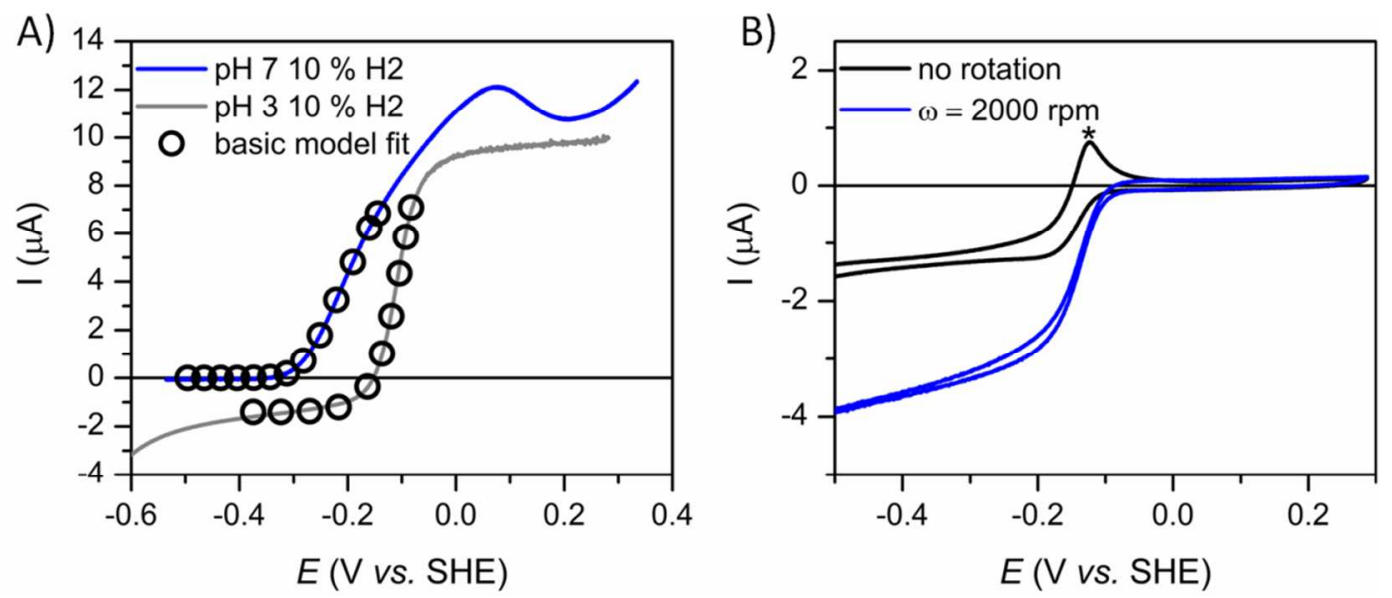

Figure 5: Converting a $\mathbf{H}_{2}$-oxidizing [NiFe]-hydrogenase into a $\mathbf{H}_{2}$ producer. A) Fits to model in Scheme $1^{7}$ to voltammograms of Hyd-1 obtained at $\mathrm{pH} 3$ and $\mathrm{pH} 7,37^{\circ} \mathrm{C}, 10 \% \mathrm{H}_{2}$. Scan rate $=10 \mathrm{mVs}^{-1}$, electrode rotation rate $=$ $2000 \mathrm{rpm}$. B) Voltammograms obtained under $100 \%$ Ar for stationary (black) and rotating electrode (blue) at $\mathrm{pH} 3$, $37{ }^{\circ} \mathrm{C}$. 
A)

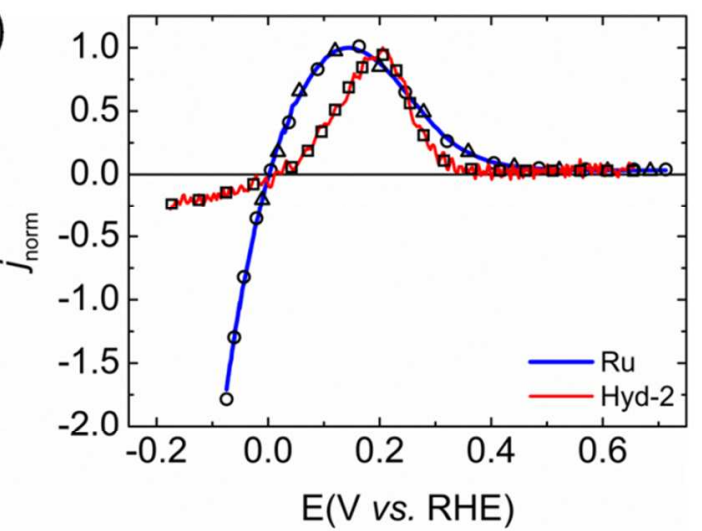

B)

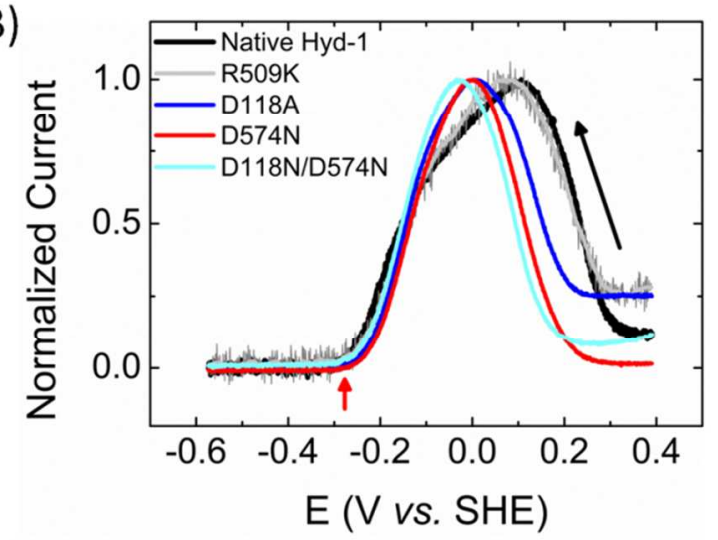

C)

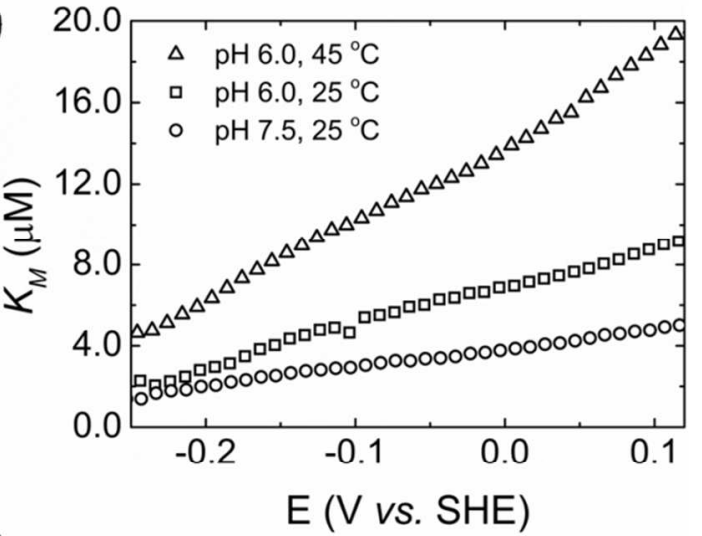

D)

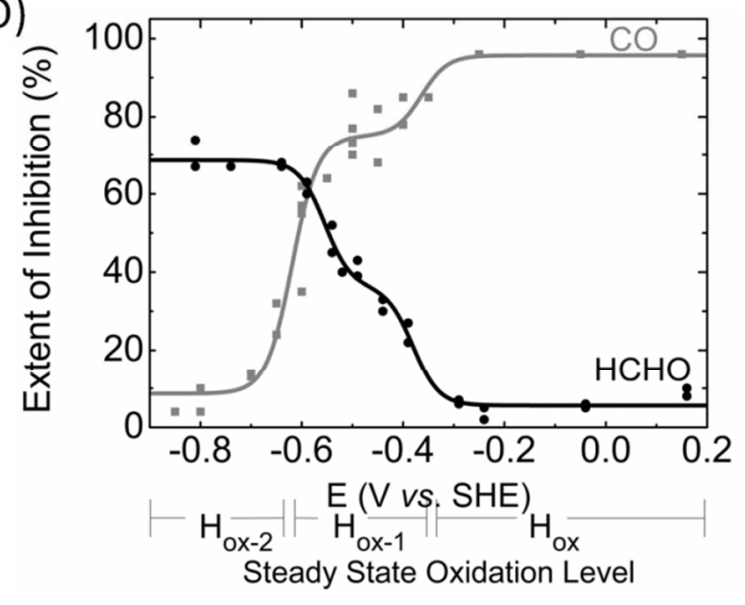

Figure 6: A. Voltammetry for $2 \mathrm{H}^{+} / \mathrm{H}_{2}$ cycling by $\mathrm{Hyd}-2$ on PGE and by a Ru (0001) electrode (fits shown as hollow shapes). B. Voltammograms $\left(0.1 \mathrm{mVs}^{-1}\right)$ comparing reductive reactivation and activity windows of Hyd-1 and 'canopy' variants at $30{ }^{\circ} \mathrm{C}$. Black arrow indicates scan direction, red arrow indicates onset potential for $\mathrm{H}_{2}$ oxidation. C. Potential dependence of $K_{\mathrm{M}}{ }^{\mathrm{H} 2}$ for Hyd-1 calculated from cyclic voltammetry experiments at $1 \mathrm{mVs}^{-1}$ under varying $\mathrm{H}_{2}$ concentrations. D. Potential dependence of the extent of inhibition of CaHydA by CO $\left(107 \mu \mathrm{M}\right.$ in $\left.80 \% \mathrm{H}_{2}\right)$ or HCHO $(4.5 \mathrm{mM}$ in $\left.100 \% \mathrm{H}_{2}\right), \mathrm{pH} 6,20{ }^{\circ} \mathrm{C}$. Data are fitted to two $n=1$ Nerstian sigmoids. 


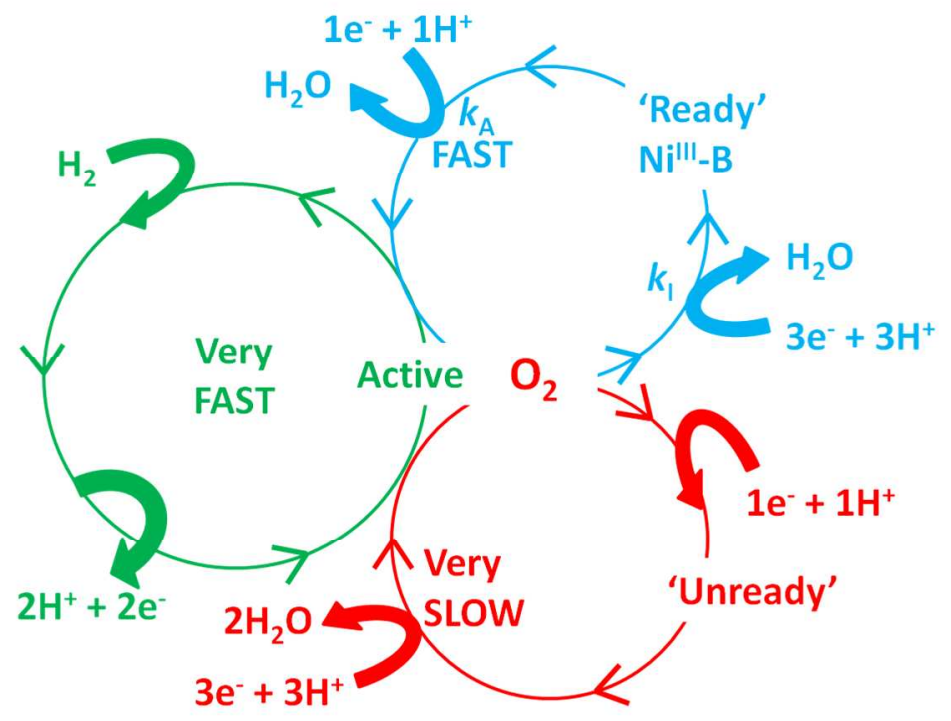

Scheme 2. ET model for $\mathrm{O}_{2}$ tolerance of [NiFe]-hydrogenases. Green: very fast $\mathrm{H}_{2}$ oxidation. Blue: fast catalytic four-electron $\mathrm{O}_{2}$ reduction producing Ni-B. Red: very slow cycle in which $\mathrm{O}_{2}$ is partly reduced, yielding oxygenated Unready (Ni-A).
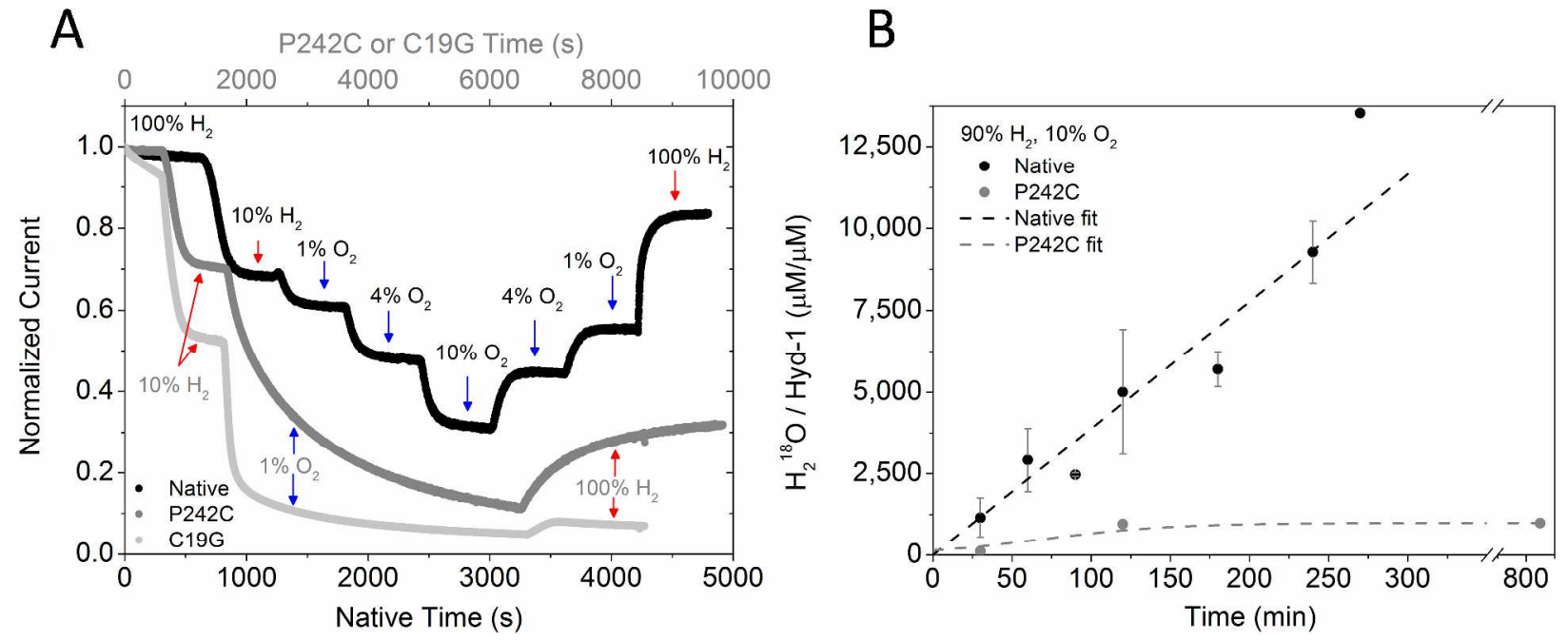

Figure 7: Demonstrating how $\mathrm{O}_{2}$-tolerant Hydrogenase-1 reacts reversibly with $\mathrm{O}_{2}$ compared to $\mathrm{O}_{2}$-sensitive variants P242C and C19G. A. $\mathrm{H}_{2}$ oxidation $\left(0 \mathrm{~V} v \mathrm{~s}\right.$. SHE, $\left.\mathrm{pH} 6,30{ }^{\circ} \mathrm{C}\right)$ by Hyd- 1 at increasing $\mathrm{O}_{2}$ concentrations reveals completely reversible reaction with $\mathrm{O}_{2}$, whereas variants cannot sustain $\mathrm{H}_{2}$ oxidation at $1 \% \mathrm{O}_{2}$. B. Formation of $\mathrm{H}_{2}{ }^{18} \mathrm{O}$ by four-electron reduction of ${ }^{18} \mathrm{O}_{2}$ continues for native enzyme, but soon ceases for P242C as Unready accumulates. ${ }^{27,33}$ 

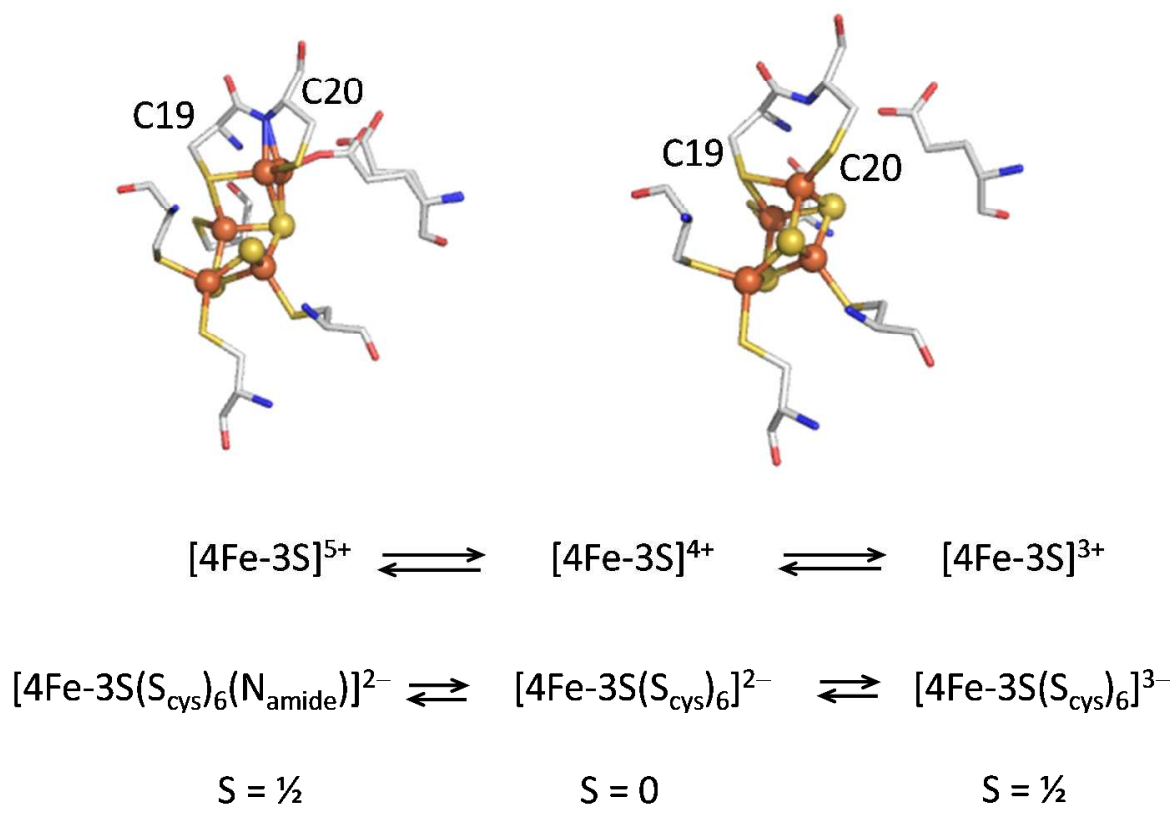

Figure 8. Structures and redox couples of the proximal cluster in Hyd-1. Upper sequence shows only the core charges whereas the lower sequence includes charges due to ligands. Spin states $(S)$ indicated.

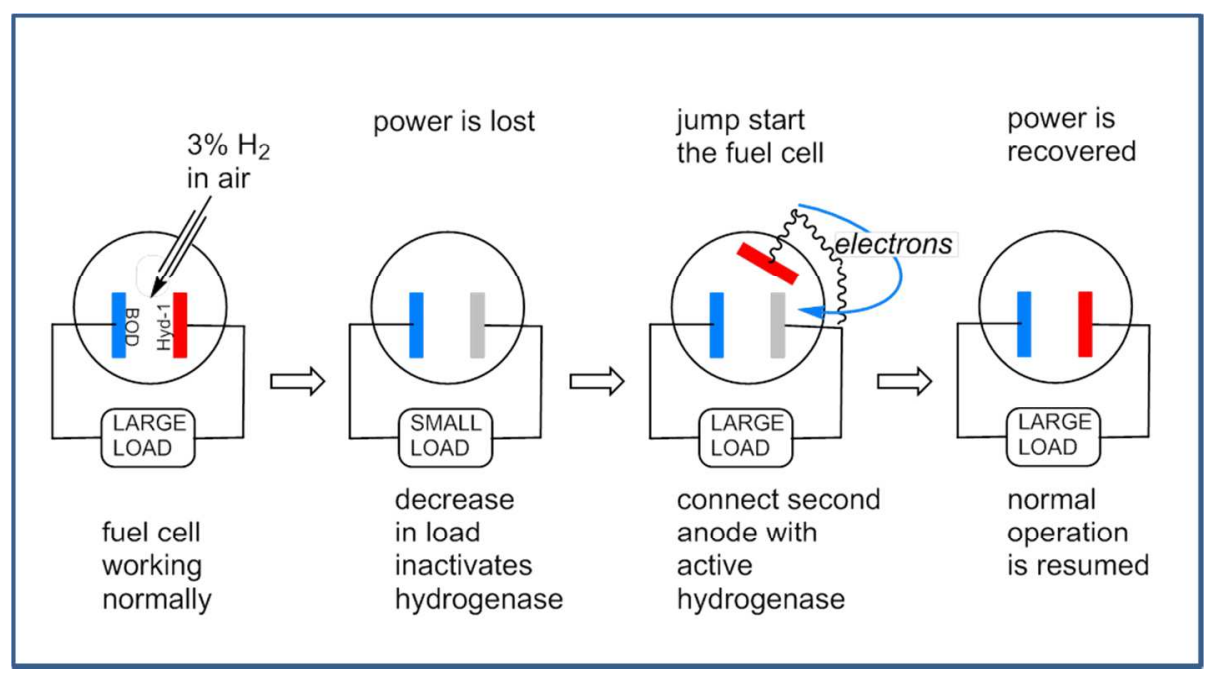

Figure 9. The 'jump-start' experiment. Enzyme fuel cell inactivated by a low-load/short-circuit is re-started using a second anode loaded with active hydrogenase. 

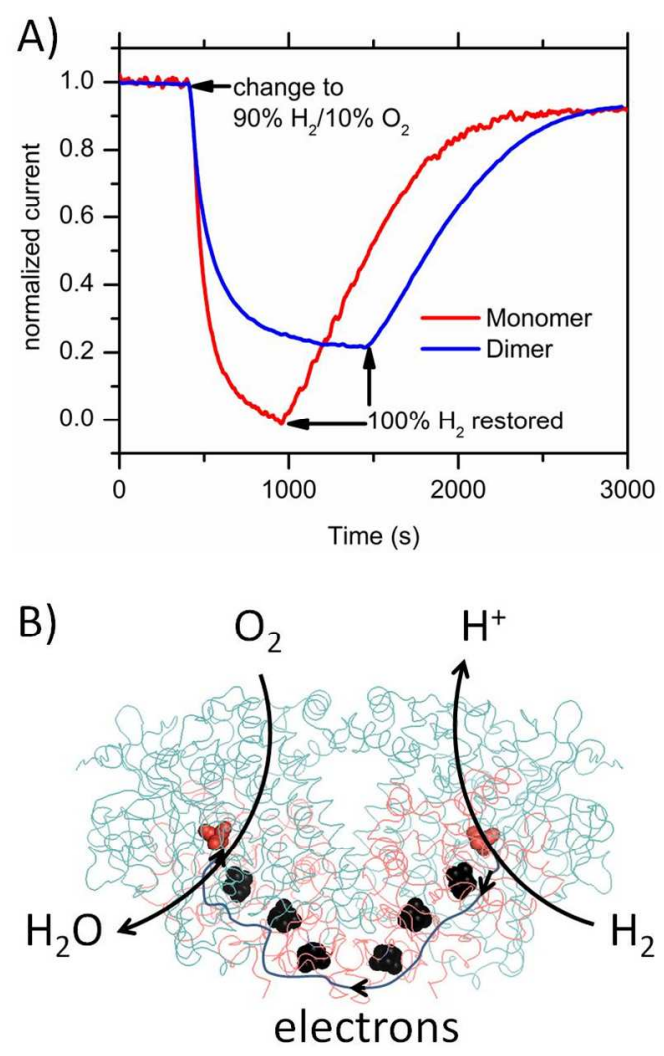

Figure 10. Evidence for the importance of intra-dimer ET in Hydrogenase-1. A) Chronoamperometric experiments to determine how $\mathrm{O}_{2}$ effects $\mathrm{H}_{2}$ oxidation by dimer and monomer forms of Hyd-1. Conditions, $25{ }^{\circ} \mathrm{C}$, $\mathrm{pH} 7$, electrode potential $+0.01 \mathrm{~V} v$ s. SHE. B) Hyd-1 as an $\mathrm{H}_{2} / \mathrm{O}_{2}$ oxidoreductase. 


\section{REFERENCES}

(1) Vincent, K. A.; Parkin, A.; Armstrong, F. A. Investigating and Exploiting the Electrocatalytic Properties of Hydrogenases; Chem. Rev. 2007, 107, 4366-4413.

(2) Lubitz, W.; Ogata, H.; Rüdiger, O.; Reijerse, E. Hydrogenases; Chem. Rev. 2014, 114, 4081-4148.

(3) Xu, L.; Armstrong, F. a. Pushing the limits for enzyme-based membrane-less hydrogen fuel cells - achieving useful power and stability; RSC Adv. 2015, 5, 3649-3656.

(4) Krishnan, S.; Armstrong, F. A. Order-of-magnitude enhancement of an enzymatic hydrogen-air fuel cell based on pyrenyl carbon nanostructures; Chem. Sci. 2012, 3, 1015-1023.

(5) Wait, A. F.; Parkin, A.; Morley, G. M.; dos Santos, L.; Armstrong, F. A. Characteristics of Enzyme-Based Hydrogen Fuel Cells Using an Oxygen-Tolerant Hydrogenase as the Anodic Catalyst; J. Phys. Chem. C. 2010, 114, 12003-12009.

(6) Hexter, S. V.; Esterle, T. F.; Armstrong, F. A. A unified model for surface electrocatalysis based on observations with enzymes; Phys. Chem. Chem. Phys. 2014, 16, 11822.

(7) Hexter, S. V.; Grey, F.; Happe, T.; Climent, V.; Armstrong, F. A. Electrocatalytic mechanism of reversible hydrogen cycling by enzymes and distinctions between the major classes of hydrogenases; Proc. Natl. Acad. Sci. USA. 2012, 109, 11516-11521.

(8) Léger, C.; Elliott, S. J.; Hoke, K. R.; Jeuken, L. J. C.; Jones, A. K.; Armstrong, F. A.; Leger, C.; Elliott, S. J.; Hoke, K. R.; Jeuken, L. J. C.; Jones, A. K.; Armstrong, F. A. Enzyme electrokinetics: Using protein film voltammetry to investigate redox enzymes and their mechanisms; Biochemistry 2003, 42, 8653-8662.

(9) Fontecilla-Camps, J. C.; Volbeda, A.; Cavazza, C.; Nicolet, Y. Structure/Function Relationships of [NiFe]- and [FeFe]-Hydrogenases; Chem. Rev. 2007, 107, 4273-4303.

(10) Evans, R. M.; Brooke, E. J.; Wehlin, S. A. M.; Nomerotskaia, E.; Sargent, F.; Carr, S. B.; Phillips, S. E. V.; Armstrong, F. A. Mechanism of hydrogen activation by [NiFe] hydrogenases; Nat. Chem. Biol. 2016, 12, 46-50.

(11) Dutta, A.; DuBois, D. L.; Roberts, J. A. S.; Shaw, W. J. Amino acid modified Ni catalyst exhibits reversible $\mathrm{H} 2$ oxidation/production over a broad $\mathrm{pH}$ range at elevated temperatures; Proc. Natl. Acad. Sci. USA. 2014, 111, 16286-16291.

(12) Berggren, G.; Adamska, A.; Lambertz, C.; Simmons, T. R.; Esselborn, J.; Atta, M.; Gambarelli, S.; Mouesca, J. M.; Reijerse, E.; Lubitz, W.; Happe, T.; Artero, V.; Fontecave, M. Biomimetic assembly and activation of [FeFe]-hydrogenases; Nature 2013, 499, 66-69.

(13) Volbeda, A.; Amara, P.; Darnault, C.; Mouesca, J.-M.; Parkin, A.; Roessler, M. M.; Armstrong, F. A.; Fontecilla-Camps, J. C. X-ray crystallographic and computational studies of the O2tolerant [NiFe]-hydrogenase 1 from Escherichia coli; Proc. Natl. Acad. Sci. USA. 2012, 109, 5305-5310.

(14) Alonso-Lomillo, M. A.; Rüdiger, O.; Maroto-Valiente, A.; Velez, M.; Rodríguez-Ramos, I.; Muñoz, F. J.; Fernández, V. M.; De Lacey, A. L. Hydrogenase-Coated Carbon Nanotubes for Efficient H2 Oxidation; Nano. Lett. 2007, 7, 1603-1608.

(15) Armstrong, F. A.; Hirst, J. Reversibility and efficiency in electrocatalytic energy conversion and lessons from enzymes; Proc. Natl. Acad. Sci. USA. 2011, 108, 14049-14054.

(16) Lukey, M. J.; Parkin, A.; Roessler, M. M.; Murphy, B. J.; Harmer, J.; Palmer, T.; Sargent, F.; Armstrong, F. A. How Escherichia coli is equipped to oxidize hydrogen under different redox conditions; J. Biol. Chem. 2010, 285, 3928-3938.

(17) Goldet, G.; Brandmayr, C.; Stripp, S. T.; Happe, T.; Cavazza, C.; Fontecilla-Camps, J. C.; Armstrong, F. a. Electrochemical kinetic investigations of the reactions of [FeFe]-hydrogenases with carbon monoxide and oxygen: Comparing the importance of gas tunnels and active-site electronic/redox effects; J. Am. Chem. Soc. 2009, 131, 14979-14989. 
(18) McDowall, J. S.; Murphy, B. J.; Haumann, M.; Palmer, T.; Armstrong, F. A.; Sargent, F. Bacterial formate hydrogenlyase complex.; Proc. Natl. Acad. Sci. USA. 2014, 111, E3948-3956.

(19) Murphy, B. J.; Hidalgo, R.; Roessler, M. M.; Evans, R. M.; Ash, P. A.; Myers, W. K.; Vincent, K. A.; Armstrong, F. A. Discovery of Dark pH-Dependent H+ Migration in a [NiFe]-Hydrogenase and Its Mechanistic Relevance: Mobilizing the Hydrido Ligand of the Ni-C Intermediate; J. Am. Chem. Soc. 2015, 8484-8489.

(20) Hidalgo, R.; Ash, P. A.; Healy, A. J.; Vincent, K. A. Infrared Spectroscopy During Electrocatalytic Turnover Reveals the Ni-L Active Site State During H 2 Oxidation by a NiFe Hydrogenase; Angew. Chem. 2015, 127, 7216-7219.

(21) Murphy, B. J.; Sargent, F.; Armstrong, F. a. Transforming an oxygen-tolerant [NiFe] uptake hydrogenase into a proficient, reversible hydrogen producer; Energ. Environ. Sci. 2014, 7, 14261433.

(22) Radu, V.; Frielingsdorf, S.; Evans, S. D.; Lenz, O.; Jeuken, L. J. C. Enhanced oxygentolerance of the full heterotrimeric membrane-bound [NiFe]-hydrogenase of Ralstonia eutropha; J. Am. Chem. Soc. 2014, 136, 8512-8515.

(23) Fourmond, V.; Infossi, P.; Giudici-Orticoni, M.-T. T.; Bertrand, P.; Léger, C.; Leger, C. "two-Step" chronoamperometric method for studying the anaerobic inactivation of an oxygen tolerant nife hydrogenase; J. Am. Chem. Soc. 2010, 132, 4848-4857.

(24) Cracknell, J. A.; Wait, A. F.; Lenz, O.; Friedrich, B.; Armstrong, F. A. A kinetic and thermodynamic understanding of $\mathrm{O} 2$ tolerance in [NiFe]-hydrogenases; Proc. Natl. Acad. Sci. USA. 2009, 106, 20681-20686.

(25) Foster, C. E.; Krämer, T.; Wait, A. F.; Parkin, A.; Jennings, D. P.; Happe, T.; McGrady, J. E.; Armstrong, F. A. Inhibition of [FeFe]-Hydrogenases by Formaldehyde and Wider Mechanistic Implications for Biohydrogen Activation; J. Am. Chem. Soc. 2012, 134, 7553-7557.

(26) Bachmeier, A.; Esselborn, J.; Hexter, S. V.; Krämer, T.; Klein, K.; Happe, T.; McGrady, J. E.; Myers, W. K.; Armstrong, F. A. How Formaldehyde Inhibits Hydrogen Evolution by [FeFe]-Hydrogenases: Determination by $<$ sup $>13</$ sup $>$ C ENDOR of Direct Fe-C Coordination and Order of Electron and Proton Transfers; J. Am. Chem. Soc. 2015, 137, 5381-5389.

(27) Evans, R. M.; Parkin, A.; Roessler, M. M.; Murphy, B. J.; Adamson, H.; Lukey, M. J.; Sargent, F.; Volbeda, A.; Fontecilla-Camps, J. C.; Armstrong, F. a. The principles of sustained enzymatic hydrogen oxidation in the presence of oxygen - the crucial influence of high potential Fe-S clusters in the electron relay of [NiFe]-hydrogenases.; J. Am. Chem. Soc. 2013, 135, 2694-2707.

(28) Stripp, S. T.; Goldet, G.; Brandmayr, C.; Sanganas, O.; Vincent, K. A.; Haumann, M.; Armstrong, F. A.; Happe, T. How oxygen attacks [FeFe] hydrogenases from photosynthetic organisms; Proc. Natl. Acad. Sci. USA. 2009, 106, 17331-17336.

(29) Swanson, K. D.; Ratzloff, M. W.; Mulder, D. W.; Artz, J. H.; Ghose, S.; Hoffman, A.; White, S.; Zadvornyy, O. A.; Broderick, J. B.; Bothner, B.; King, P. W.; Peters, J. W. [FeFe]-hydrogenase oxygen inactivation is initiated at the $\mathrm{H}$ cluster 2Fe subcluster.; J. Am. Chem. Soc. 2015, 137, 1809-1816.

(30) Orain, C.; Saujet, L.; Gauquelin, C.; Soucaille, P.; Meynial-Salles, I.; Baffert, C.; Fourmond, V.; Bottin, H.; Léger, C. Electrochemical Measurements of the Kinetics of Inhibition of Two FeFe Hydrogenases by $\mathrm{O} 2$ Demonstrate That the Reaction Is Partly Reversible.; J. Am. Chem. Soc. 2015, 137, 12580-12587.

(31) Volbeda, A.; Martin, L.; Barbier, E.; Gutiérrez-Sanz, O.; De Lacey, A. L.; Liebgott, P.-P.; Dementin, S.; Rousset, M.; Fontecilla-Camps, J. C. Crystallographic studies of [NiFe]-hydrogenase mutants: towards consensus structures for the elusive unready oxidized states; J. Biol. Inorg. Chem. 2015, 20, 11-22.

(32) Lukey, M. J.; Roessler, M. M.; Parkin, A.; Evans, R. M.; Davies, R. A.; Lenz, O.; Friedrich, B.; Sargent, F.; Armstrong, F. A. Oxygen-Tolerant [NiFe]-Hydrogenases: The Individual and Collective 
Importance of Supernumerary Cysteines at the Proximal Fe-S Cluster; J. Am. Chem. Soc. 2011, 133, 16881-16892.

(33) Wulff, P.; Day, C. C.; Sargent, F.; Armstrong, F. A. How oxygen reacts with oxygentolerant respiratory [NiFe]-hydrogenases; Proc. Natl. Acad. Sci. USA. 2014, 111, 6606-6611.

(34) Roessler, M. M.; Evans, R. M.; Davies, R. A.; Harmer, J.; Armstrong, F. A. EPR spectroscopic studies of the Fe-S clusters in the O2-tolerant [NiFe]-hydrogenase Hyd-1 from E. coli, and characterization of the unique [4Fe-3S] cluster by HYSCORE; J. Am. Chem. Soc. 2012, 134, 15581-15594.

(35) Volbeda, A.; Darnault, C.; Parkin, A.; Sargent, F.; Armstrong, F. A.; Fontecilla-Camps, J. C. Crystal Structure of the O2-Tolerant Membrane-Bound Hydrogenase 1 from Escherichia coli in Complex with Its Cognate Cytochrome b; Structure (London, England: 1993) 2013, 21, 184-190.

(36) Wulff, P.; Thomas, C.; Sargent, F.; Armstrong, F. A. How the oxygen tolerance of a [NiFe]hydrogenase depends on quaternary structure; J. Biol. Inorg. Chem. 2016, 21, 121-134. 


\section{CONCLUSIONS}

Were we to view this research purely from an electrochemist's standpoint, notable aspects would be the contribution of hydrogenases to promoting an alternative understanding of electrocatalysis and improving our expectations of what should be possible through clever design and synthesis. Hydrogenases are among many enzymes now known to exhibit high electrocatalytic activity that is reversible close to the thermodynamic potential -a property that is absent for almost all small molecule catalysts and materials. Living organisms, relying on an energy resource that is restricted in potential, must minimize the overpotential required to drive reactions: hence it is no wonder that evolution took good heed of electrochemical principles. The availability of a wide variety of different hydrogenases from various organisms, along with the ability to alter the active sites and internal electron relays by site-directed mutagenesis, is leading to an rational understanding of electrocatalysis -one that is not only concerned with maximizing rate and efficiency, but also in understanding inhibition and minimizing detrimental side reactions.

Looked at from a biological viewpoint, dynamic electrochemical techniques are revolutionizing the study of catalytic electron flow through complex enzymes, revealing the interplay between steady-state rate and potential. A notable feature of PFE is the ability to reveal the catalytic activity of a tiny quantity of redox enzyme as a characteristic current-potential relationship. More than just a fingerprint, the voltammogram reveals properties that are not apparent from conventional solution methods and instigates new experiments to follow up, expand and resolve these observations at a structural level. As components of the electronic circuits of life, it is very appropriate that large redox enzymes can be interrogated physically to measure their response to a voltage step or contact with external reagents. Hydrogenase experts have always distinguished ' $\mathrm{H}_{2}$-uptake' and ' $\mathrm{H}_{2}$ evolving' enzymes based on solution assays, but PFE experiments reveal such bias in a direct and quantitative way and offer explanations why a particular enzyme should appear to operate in a particular direction. The connection between electronics and enzyme catalysis may be unorthodox, but it continues to provide new insight to the field of $\mathrm{H}_{2}$ activation that has long brought together coordination chemists and enzymologists. 